DOI 10.37882/2223-2982.2020.04-2.36

\title{
ФРАНЦУЗСКАЯ И АМЕРИКАНСКАЯ ШКОЛА КЛАССИЧЕСКОГО САКСОФОНА: СРАВНИТЕЛЬНЫЙ АНАЛИЗ МЕТОДИКИ ПРЕПОДАВАНИЯ
}

\section{FRENCH AND AMERICAN SCHOOL OF CLASSICAL SAXOPHON: COMPARATIVE ANALYSIS OF TEACHING METHODS}

Jiang Wenjie

Summary: The article is devoted to the issues of teaching saxophone teaching methods within the framework in two classical teaching approaches developed by two famous teachers: French teacher and saxophonist Marcel Mule and his American colleague, Larry Teal. The purpose of the article is to identify the features of two classical approaches to learning the saxophone in French and American traditions. The objectives of the study are to disclose the basic principles of the pedagogical system by Marcel Mule; identifying the features of the technique by Larry Teal; comparing two schools on the basis of historical criteria for the development of teaching methods.

The research methodology consists of the general scientific methods (analysis, synthesis, deduction, induction) and includes special methods: a content analysis of scientific literature on the topic of research, a retrospective analysis method. The scientific novelty of the article lies in the fact that the specificity of the teaching methodology of the classical saxophone is considered in a historical perspective, and all the basic principles of two pedagogical schools are summarized as part of a comparative analysis. From the practical significance point of view, the materials and conclusions of the article can be used for special courses in such subjects as "music literature" and "methods of teaching the classical saxophone". The author of the article concludes that at the present stage, the differences between the two methodological systems for teaching the classical saxophone are beginning to gradually level due to the process of international exchange of knowledge and the rapid globalization of the process of teaching music. Nevertheless, the main characteristic features of the French and American pedagogical systems remain to this day and can be clearly identified thanks to the comparative analysis carried out in the article.

Keywords: classical saxophone; vibrato, tone, Marcel Mule's pedagogical system, Larry Teal's pedagogical system, French and American classical saxophone schools.

\author{
Цзян Вэньцзэ, \\ ассистент-стажер, ФГБОУ ВО «Российская академия \\ музыки имени Гнесиных» \\ 68789265@q9.com
}

Аннотация: Статья посвящена вопросам методики преподавания игры на саксофоне в рамках двух классических подходов к обучению, разработанных двумя знаменитыми преподавателями: французским педагогом и саксофонистом Марселем Муле и его американским коллегой Ларри Тилом. Цель статьи заключается в выявлении особенностей двух классических подходов к обучению игре на саксофоне в рамках французской и американской традиций. Задачи исследования состоят в раскрытии основных принципов педагогической системы Марселя Муле; выявлении особенностей методики Ларри Тила; проведении сравнения двух школ на основе исторического критерия развития методики преподавания.

Методология исследования состоит из группы общенаучных методов (анализ, синтез, дедукция, индукция); а также включает специальные методы: контент-анализ научной литературы по теме исследования, метод ретроспективного анализа.

Научная новизна статьи заключается в том, что специфика методики преподавания классического саксофона рассматривается в исторической перспективе. В статье также суммируются все основные принципы двух педагогических школ в рамках сравнительного анализа.

С точки зрения практической значимости, материалы и выводы статьи могут быть использованы для чтения специальных курсов по таким предметам, как «музыкальная литература» и «методика преподавания классического саксофона».

Автор статьи приходит к выводу, что на современном этапе различия между двумя методологическими системами преподавания классического саксофона начинают постепенно нивелироваться благодаря процессу международного обмена знаниями и стремительной глобализацией обучения музыке. Тем не менее, ключевые характерные особенности французской и американской педагогических систем сохраняются по сей день и могут быть достаточно четко идентифицированы благодаря проведенному в статье сравнительному анализу.

Ключевые слова: классический саксофон; вибрато, тон, педагогическая система Марселя Муле, педагогическая система Ларри Тила, французская и американская школы классического саксофона.

учреждений постоянно пополняется и развивается, синтезируя традиционные подходы и классические принципы в новые модели преподавания. Поэтому в рамках современных исследований, посвященных музыкальной педагогике, необходимо больше внимания уделять сравнительному анализу методологии преподавания в различных национальных школах. Проблема, связанная 
с отсутствием компаративных исследований в области методологии преподавания, особенно остро ощущается в сфере преподавания игры на саксофоне, поскольку данный инструмент, как и репертуар для него, имеет собственную специфику. В связи со сложившейся ситуацией в историографии вопроса, нами проведено сравнительное исследование в области методологии преподавания игры на саксофоне во французской и американской школах, признанных на сегодняшний день классическими.

Высочайшее качество музыки и исторически обоснованные концепции классического исполнения представлены в симфоническом оркестре. Это не означает, что другие стили не являются музыкальными или не соответствуют стандартам, однако инструментальная музыка в западноевропейской культуре концептуально развивалась в основном из симфонической традиции, поскольку именно эта форма инструментальной музыки пользовалась наибольшим одобрением европейского общественного сознания [1, с.11].

В силу такой общей тенденции, в развитии западноевропейской музыкальной классической традиции методология французской школы игры на саксофоне выстраивалась на основании применении музыкальной концепции симфонических духовых к саксофону, несмотря на то, что этот подход, на наш взгляд, нельзя назвать полностью релевантным для некоторых из предлагаемых стилистических решений. Использование вибрато - одна из таких концепций, которая оспаривается на протяжении всей истории педагогики саксофона: некоторые исследователи полагают, что саксофон изначально не был предназначен для игры с приемом вибрато [7, с.22].

Вероятно поэтому, основатель французской классической педагогической модели игры на саксофоне Марсель Муле, впервые разработал принципы вибрато для саксофона [10, с.24]. Другие историки музыки полагают, что впервые вибрато для саксофона, в рамках стремления к сближению этого инструмента с классическими западноевропейскими музыкальными традициями, было разработано Сигурдом Рашером [6] - американским саксофонистом с немецкими корнями. Однако мы считаем, что прием вибрато является классическим для всех духовых инструментов, поэтому только по данному критерию невозможно выявить отличия между двумя классическими школами саксофона - французской (западноевропейской) и американской.

В историографии вопроса также существует мнение о том, что классическая французская школа саксофона основана на принципе исполнения музыки так, как задумал композитор. Это никоим образом не означает, что каждый саксофонист должен играть любую музыкальную пьесу одинаково, теряя индивидуальность, суть в том, что он должен воспроизводить музыку так, чтобы она точно отображала то, что написал композитор [8, с.207].

В некоторых исследованиях можно также найти разрозненные упоминания некоторых классических принципов преподавания игры на саксофоне [5,4,3], однако подробного анализа методов и приемов до сих пор не проводилось.

На наш взгляд, педагогические методы в двух национальных школах имеют как отличия, так и сходства. С этой позиции можно говорить о том, что французская школа классического саксофона неотделима от наследия ее основателя Марселя Муле. От разработки характерного качества тона и использования классического вибрато до создания стандартного квартета саксофонов и большей части сольного репертуара саксофона, Марсель Муле оказал огромное влияние на рост позитивного восприятия саксофона как классического инструмента. Кроме того, его тепло и честность как личности в сочетании с его непревзойденным мастерством и тщательными педагогическими методами позволили ему оказать глубокое влияние на огромное количество саксофонистов во всем мире. По словам одного из его учеников, Даниэля Деффайе: «Пусть все классические саксофонисты никогда не забудут, что благодаря Марселю Муле они сегодня считаются настоящими музыкантами» [7, с.118]. Педагогические принципы Марселя Муле стали основой для класса саксофона в Национальной консерватории в Париже, специально созданного в 1942 году. По сей день французская школа преподавания игры на саксофоне включает следующие основные принципы, которые были сформулированы Марселем Муле:

- особые требования к звукоизвлечению - «классическое вибрато Муле» (разработка навыка быстрого и жесткого вибрато малого диапазона);

- достижение тона имитации голоса с помощью хорошей воздушной поддержки и амбушюра, который не зажимает тростниковую трубку инструмента;

- преподавание основано на постоянном совершенствовании технических навыков исполнения;

- исполнительские навыки вторичны по отношению к техническим (возникают как результат технического мастерства);

- индивидуальный подход к каждому ученику;

- результаты обучения непосредственно соответствуют способностям ученика.

На наш взгляд, именно создание специфического тона для французской школы классического саксофона является приоритетом. Более того, и тон, и вибрато, согласно принципам преподавания Марселя Муле, должны моделировать женский голос. Такой эффект достигается именно при максимальной воздушной поддержке и амбюшора, не зажимающего тростниковую трубку. 
Специфика французской школы преподавания игры на саксофоне также заключается в уникальной концепции вибрато, которая так характерна для западноевропейской традиции использования духовых инструментов. В преподавании игры на саксофоне огромное значение имеет создание волнообразных звуков как способа придать звучанию саксофона естественный характер, поскольку «подобные волны органически существуют в окружающем нас мире» [9, с.22].

Французские педагоги призывают своих учеников использовать метроном, чтобы получить контроль и равномерность в скорости вибрато. Наиболее релевантным считается жесткое, быстрое вибрато со скоростью 300 волн в минуту, чего можно добиться, установив метроном на 76 ударов в минуту и волнообразный ритм 4 раза за удар [10, с.77]. Для французской школы преподавания игры на саксофоне также характерно широкое использование метронома при исполнении этюдов и арпеджио, несмотря на существующие критические отзывы о том, что практика с метрономом приводит к механическому звукоизвлечению [10, с.78]. По сути, вся педагогическая концепция французской школы игры состоит в том, что сначала нужно научиться играть в рамках жесткой дисциплины, прежде чем играть со свободой и самовыражением [10, с.79]. Таким образом, именно технический аспект исполнения, который менее трудно преподавать, является базой, на которой строится в последующем преподавании требуемого тона, вибрато, музыкальной выразительности и уверенности исполнения. То есть приоритет отдается техническим навыкам как базе для исполнительского мастерства. Такой подход является, на наш взгляд, классическим для всей западноевропейской музыкальной традиции и призван, по сути, внедрить саксофон к общее русло классической симфонической музыки.

Американская школа саксофона, ставшая классической благодаря методологическим принципам преподавания Ларри Тила, возникла в 1930-х годах в Бостоне и имеет свои особенности. В то время Ларри Тил - основатель американской классической школы преподавания игры на саксофоне, уже преподавал многочисленным студентам в районе Детройта в формате частных уроков, однако вскоре, летом 1936 года, Ларри Тил был назначен преподавателем первого курса саксофона в музыкальной школе «Chautauqua» в Нью-Йорке [3, с.4]. В дальнейшем Ларри Тил сформулировал следующие принципы преподавания игры для классического саксофона:

- особые требования к звукоизвлечению - «джазовое вибрато» (разработка навыка глубокого и медленного вибрато широкого диапазона);

- достижение тона с помощью воздушной поддержки;

- преподавание основано на постоянном совершенствовании исполнительских навыков;
- исполнительские навыки первичны по отношению к техническим (возникают как результат самовыражения, а не технического мастерства);

- обучение в малых группах;

- результаты обучения должны максимально отражать способности ученика.

Как и Марсель Муле во французской педагогической традиции, так и Ларри Тил был необычайно влиятельной фигурой в развитии классического саксофона, в первую очередь - в сфере преподавания. Более того, авторская методика преподавания Ларри Тила была разработана всего на четыре года позднее, чем принципы, сформулированные его французским коллегой.

Несмотря на очевидное сходство основных идей, на педагогические концепции музыкантов неизбежно повлияли культурные различия между Парижем и Детройтом в начале 1900-х годов. Фактически именно отличия в педагогических принципах игры и обучения привели к возникновению двух профессиональных (французской и американской) школ классической игры на саксофоне.

Интересно отметить, что ни Марсель Муле, ни Ларри Тил формально не получили академического образования по классу саксофона в начале своей карьеры. Одна из причин этого заключалась в том, что в то время они не могли изучать саксофон в музыкальном академическом учреждении - классов этого инструмента просто не существовало, поскольку его не признавали классическим. Поэтому оба музыканта вынуждены были посвятить свое время разработке конкретных саксофонных техник и педагогических методов.

Однако со временем Ларри Тил, в отличие от Марселя Муле, пошел по академическому пути и в итоге получил степень доктора музыки в Институте музыкального искусства в Детройте [5, с.123]. Формальное музыкальное образование, которое Ларри Тил получил позже в своей карьере, несомненно, повлияло на методы его преподавания в Мичиганском университете, что определило, на наш взгляд, вектор развития американской школы классического саксофона: американские педагоги больше придерживаются академических канонов, чем французские преподаватели.

В американской педагогической школе игры на саксофоне музыка рассматривается не только как искусство, но и как научная деятельность, поэтому американские педагоги ориентированы на четко организованную учебную программу обучения, принципы которой были заложены Ларри Тилом. Французская школа игры на саксофоне, основанная Марселем Муле, который сам не принадлежал к академическим научным кругам, изначально не придерживалась жестких академических стандартов преподавания. Акцент на академических научных 
знаниях все еще можно увидеть в американской школе классического саксофона и в настоящее время [4].

Другим различием между школами Марселя Муле и Ларри Тила является то, что американские преподаватели уделяют гораздо больше времени формированию у своих учеников исполнительских навыков, а технические вопросы считают вторичными [2]. Вероятно, это объясняется тем, что Ларри Тил проработал более 20 лет профессиональным кларнетистом и флейтистом, в то время как Марсель Муле в основном занимался разработкой концепции игры на саксофоне. Особенности профессиональных интересов двух музыкантов, на наш взгляд, стали также причиной различий в репертуаре для саксофона: Ларри Тил придерживался жанра «джаз» в большей степени при подборе учебного репертуара, в то время как Марсель Муле в основном ориентировался на этюды и аранжировки классических музыкальных произведений, большую часть из них создавая и перерабатывая самостоятельно.

Интересно отметить, что, хотя джаз, безусловно, существовал в Париже в начале 1900-х годов, он был гораздо больше органичным явлением для американской культуры, чем французской музыкальной традиции. В результате джазовая составляющая учебного репертуара в большей степени характерна для американской школы преподавания игры на саксофоне. Следствием этого стала разработка отличного от французского приема вибрато - американская школа, основоположников которой является Ларри Тил, предпочитает более глубокий, под влиянием джаза, тон с более медленным вибрато и более широким диапазоном [6]. Во французской школе больше внимания уделяется тем, произведениям, которые написал сам Марсель Муле, в американской педагогической традиции джазовая композиция преподаются отдельным курсом [7, с.78].

С нашей точки зрения, влияние, которое Марсель Муле оказал на развитие методической и учебной литературы для преподавания классической игры на саксофоне, является более значительным, чем вклад Ларри Тила. В частности, Марсель Муле написать довольно много собственных этюдов, чтобы дополнить учебные материалы Парижской консерватории, а также произвел немало аранжировок этюдов для саксофона всемирно признанных композиторов.

Если французская педагогика опирается на принцип индивидуального подхода к преподаванию и отдает приоритет сольному исполнению и сольной программе, то в американской системе академического обучения акцент делается на групповые занятия (в основном занятия в малых группах), то есть широко используется принцип ансамблевого исполнения. Для американской школы игры на саксофоне традиционным считается распределение учеников в трио, квартеты и более крупные саксофонные ансамбли для работы над интонацией, мелодическим синтезом в рамках технологии сотрудничества [8].

Для американской школы также характерно широкое применение аранжировки большей части репертуара струнного квартета для саксофонного квартета из сопрано, альта, тенора и баритона [9, с.12]. Американскую школу преподавания игры на саксофоне также отличает наличие четких методических основ игры на саксофоне, сформулированных Ларри Тилом. В книге «Искусство игры на саксофоне» он подробно описывает все вопросы, касающиеся саксофона, включая правильные методы дыхания, игровое положение, амбушюр, вибрато, качество тона и настройки тростниковой трубки [10, с.101].

В настоящее время в американской школе классического саксофона приняты следующие методические принципы игры: ученики должны установить верхние зубы на верхней части мундштука, чтобы закрепить амбушюр и обеспечить стабильный цветовой тон звука; дыхание должно происходить без удаления верхних зубов от мундштука, в то время как горло должна быть открыто полностью [9, с.14]. Что касается артикуляции, она осуществляется посредством языка, который рассматривается как устройство для остановки вибрации тростниковой трубки, но не для остановки воздуха. Категорически запрещены движения челюстью во время вибрато, чтобы предотвратить искажение высоты звука и тона [9, с.14].

На наш взгляд, различия во французской и американской концепции звукоизвлечения легко заметить, прослушав записи Марселя Муле и Ларри Тила. Звук французской школы значительно ярче, чем звук американской, и в некоторые моменты похож на звук скрипки, в то время как звук американской школы Ларри Тила более темный и мягкий, иногда звучит как кларнет.

Основные отличия двух школ представлены на рисунке 1.

На наш взгляд, на принципы звукоизвлечения в двух школах мог повлиять тот факт, что один из учителей Марселя Муле, Габриэль Виллом, был скрипачом, а Ларри Тил провел большую часть своей профессиональной карьеры в качестве оркестрового кларнетиста [6]. Однако самое заметное различие в методике преподавания двух школ заключается в особенностях вибрато. Французская школа поддерживает чрезвычайно быстрое и жесткое вибрато, поскольку считается, что существует правильная скорость волнистости, которую всегда следует соблюдать [2].

Напротив, американские педагоги, вслед за Ларри Тилом, полагают, что, если вибрато всегда применять одинаково, оно становится однообразным, а также что 


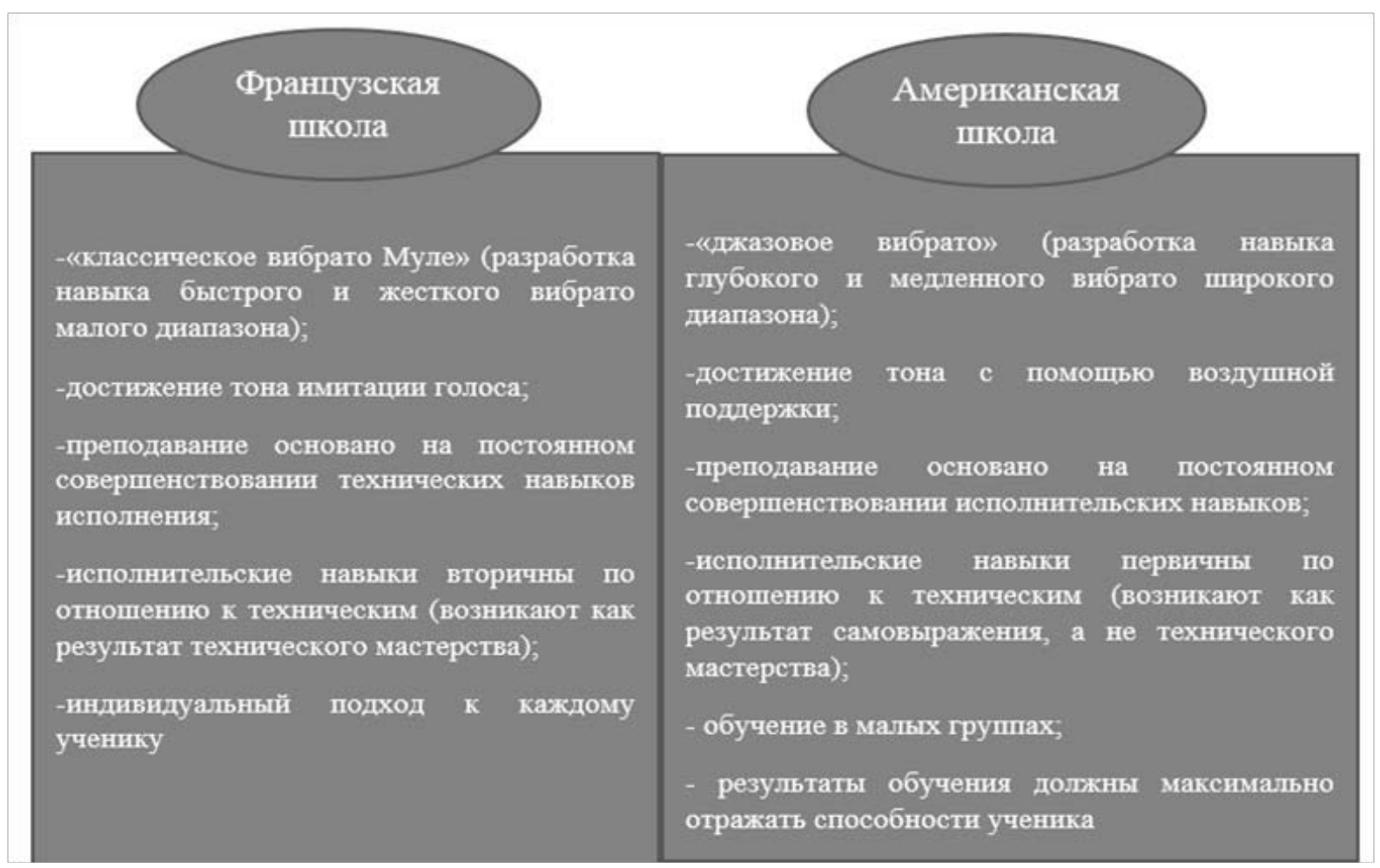

Рис. 1. Основные принципы французской и американской школ игры на саксофоне

вибрато должно быть гибким и использоваться как форма музыкального выражения [9]. Исполнение учеников американской школы игры на саксофоне можно легко отличить от французской школы, поскольку используется немного более медленное вибрато при игре в медленных темпах или тихой динамике, и более быстрое вибрато при игре в более быстрых темпах и более громкой динамике. Большинство современных саксофонистов приняли эту концепцию и реализуют ее в еще более заметной степени.

Однако, несмотря на выявленные нами отличия французской и американской школ, с каждым новым поколением саксофонистов, различия в звукоизвлечении становятся все более размытыми, что делает контраст между французской и американской школами менее очевидным. В современном музыкальном образовании отличия между французской и американской школами нивелируется также потому, что многие саксофонисты учились у нескольких учителей, иногда пересекая ме- тодическую грань между французской и американской школами.

Например, Джон Сэмпен, профессор саксофона в Государственном университете Боулинг-Грин, учился у Ларри Тила и Фредерика Хемке, ученика Марселя Муле. По этой причине Джон Сэмпен и многие другие выдающиеся саксофонисты сегодня находятся под влиянием обеих педагогических школ, и их ученики также осваивают принципы обеих концепций. Вся история классического саксофона все еще относительно молода, и большинство современных саксофонистов все еще не осуществляют поиск новых методических идей для обучения игре на саксофоне. Можно предположить, что различия между французской и американской школами со временем будут становиться все менее очевидными, но основные принципы, которые сформулировали Марсель Муле и Ларри Тил, остаются основными векторами развития методологии классического саксофона.

\section{ЛИТЕРАТУРА}

1. Авилов В.Н. Мировая джазовая культура в контексте обучения игре на саксофоне // Проблемы современного педагогического образования. 2018. № 3. C. 11-15.

2. Назарьян А.А. Исполнительские навыки игры на саксофоне // Проблемы современной науки и образования. 2018. № 1. - С. 1-3.

3. Понькина А.М. Американская исполнительская школа: особенности обучения игре на саксофоне // Universum: филология и искусствоведение. 2017. № 2. C. 2-6. 
4. Понькина А.М. Влияние джаза на эволюцию академического искусства игры на саксофоне // Вестник Томского государственного университета. Культурология и искусствоведение. 2019. № 3. - С. 137-143.

5. Понькина А.М. Методологические принципы Ларри Тила и их роль в эволюции исполнительства на саксофоне второй половины XX столетия // Манускрипт. 2017. № 2. - С. 122-124.

6. Eriksson E. (2012). Finding pedagogical strategies for combined classical and jazz saxophone applied studies at the college level. University of Northern Colorado Scholarship \& Creative Work. Dissertations. URL: https://digscholarship.unco.edu/cgi/viewcontent.cgi?article=1117\&context=dissertations

7. Hemke F.L. (2018). Le Maitre: Memories of The Master Teacher/Musician, Marcel Mule. School of Music, Northwestern University, Evanston, Illinois. - 124 p.

8. Miracle S.E. (2015). An Exploration of the French and American Schools of Classical Saxophone. Honors Research Projects. - Pp. $206-222$.

9. Rebbeck L. (2019). A Practical Guide for Teaching the Saxophone to Beginners. FriesenPress. - $169 \mathrm{p}$.

10. Rousseau E. (2019). Marcel Mule. Saxophonist and Teacher. Dorn Publications. - 155 p.

( Цзян Вэньцзэ (68789265@qq.com).

Журнал «Современная наука: актуальные проблемы теории и практики»

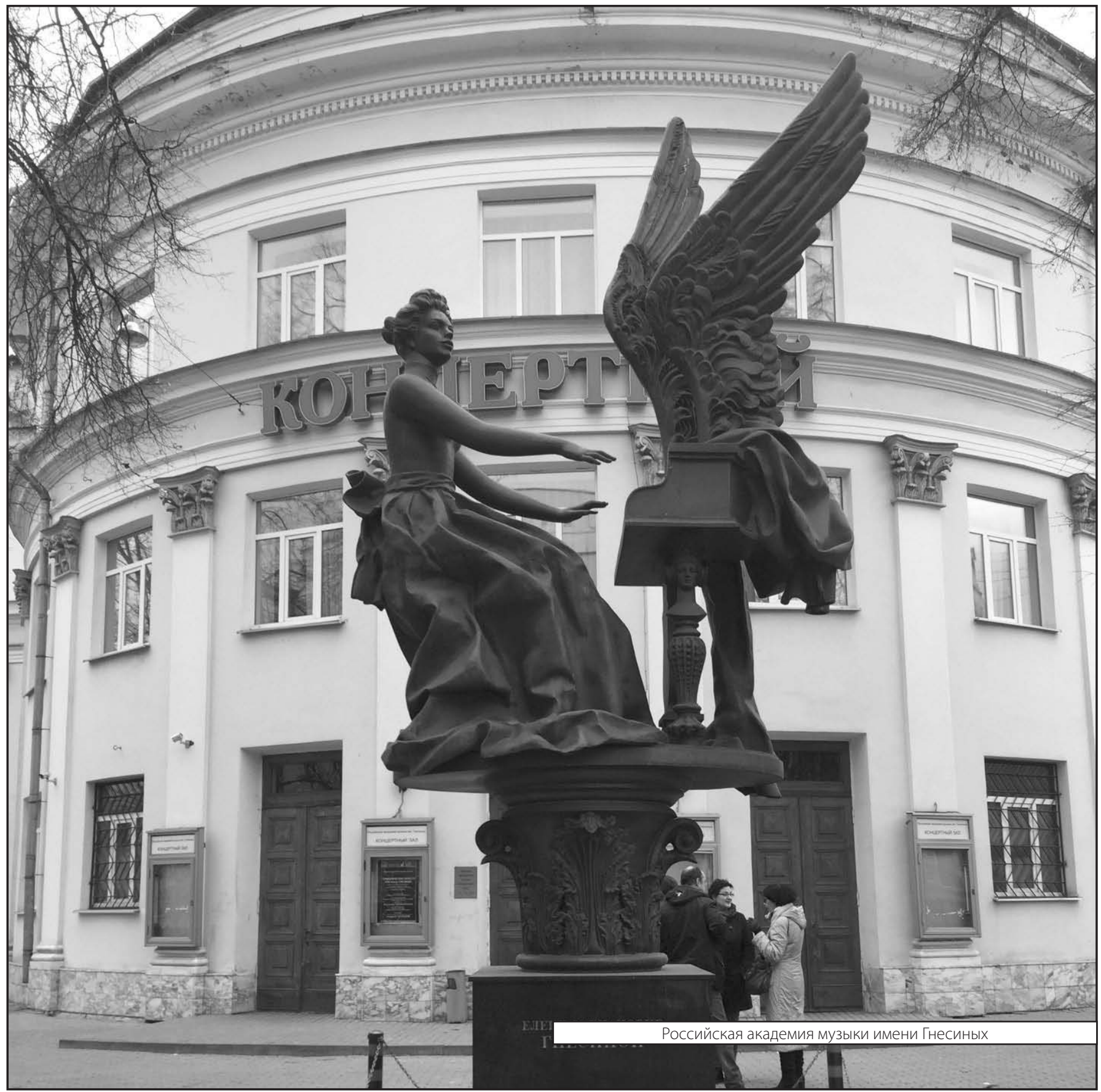

